\title{
Viabilidade do uso de árvores ocas da espécie Astronium lecointei Ducke por meio da utilização da tecnologia da madeira e do design
}

\author{
Viability of the use of hollow trees of \\ Astronium lecointei Ducke using wood \\ technology and design
}

\author{
Suzana Helen da Silva Medeiros ${ }^{1}$, Claudete Catanhede do Nascimento ${ }^{2}$, \\ Geislayne Mendonça Silva ${ }^{3}$
}

\footnotetext{
${ }^{1}$ Universidade Federal do Amazonas, Departamento de Ciências Agrárias, CEP: 69080-900, Manaus, AM, Brasil. ${ }^{2}$ Instituto Nacional de Pesquisas da Amazônia - INPA, Laboratório de Engenharia e Artefatos de Madeira - LEAM, CEP: 69.067-375, Manaus, AM, Brasil.

${ }^{3}$ Universidade Federal de Campina Grande, CEP: 58429-140, Campina Grande, PB, Brasil.

e-mail: suzanamedeiros93@gmail.com, catanhed@inpa.br.gov geislayne94@gmail.com
}

\section{RESUMO}

Com a falta de tecnologia no setor florestal, alternativas são necessárias para favorecer a maximização do uso da madeira amazônica, principalmente àquelas que possuem características desfavoráveis para o seu processamento. Assim, o objetivo da pesquisa foi desenvolver o projeto de um produto com o design planejado, confeccionando-o e verificando as etapas de processamento para atestar o aumento do rendimento volumétrico e a diminuição dos resíduos de madeiras proveniente de árvores ocas. Com isso, foi projetado um móvel, utilizando softwares para modelar as alternativas de geometria e encaixe para uma mesa de jantar com seis lugares, com estrutura e formas diferenciada. Foram utilizados cerca de $0,1799 \mathrm{~m}^{3}$ de madeira da espécie de Muiracatiara para a confecção da mesa, possuindo acabamento fino e técnicas de marchetaria no tampo, com madeira de Marupá. A volumetria final do produto foi igual a $0,5420 \mathrm{~m}^{3}$, sendo o rendimento volumétrico de $30,13 \%$ considerado alto, para a quantidade de madeira utilizada no processo. Com o restante, cerca de 69,87\% de resíduo madeireiro da produção da mesa, foi possível realizar a confecção de uma luminária, a partir de peças descartadas durante a usinagem da madeira. O estudo permitiu a demonstração da aplicabilidade do design no setor madeireiro a partir do planejamento do uso da matéria prima, onde foi possível verificar a viabilidade do procedimento utilizando madeira amazônica para a confecção de itens domésticos, independente do estado de qualidade, tornando a atividade sustentável ao setor.

Palavras-chave: Madeira Amazônica, Tecnologia florestal, Rendimento Volumétrico, Design de produtos.

\section{ABSTRACT}

With the lack of technology in the forest sector, alternatives are necessary to favor the maximization of the use of Amazonian wood, especially to those that have unfavorable characteristics for its processing. Thus, the objective of the research was to develop the design of a product with the planned design, making it and verifying the processing steps to attest the increase of the volumetric yield and the reduction of wood residues from hollow trees. With this, furniture was designed, using software to model the geometry and fitting alternatives for a six-seat dining table, with different structure and shapes. About $0.1799 \mathrm{~m}^{3}$ of Muiracatiara wood was were used to make the table, with marquetry technique on top, with Marupá wood. The final volume of the product was $0.5420 \mathrm{~m}^{3}$, and the volume yield was $30.13 \%$ considered high, for the quantity of wood used in the process. With the remainder, about $69.87 \%$ of lumber residue from table production, it was possible to make a luminaire, from discarded pieces during the wood machining. The study allowed the demonstration of the applicability of the design in the wood sector from the planning of the use of the raw material, where it 
was possible to verify the feasibility of the procedure using amazonic wood for the making of household items, regardless of state of quality, making the activity sustainable to the sector.

Keywords: Amazonian Wood, Forestry Technology, Volumetric Yield, Product Design.

\section{INTRODUÇÃO}

A floresta amazônica é a maior reserva contínua de floresta tropical úmida existente, com características complexas, tanto de carácter ambiental quanto sociocultural [11, 16]. A partir do grande volume madeireiro nessa região, o alto potencial das atividades de exploração florestal ficou evidenciado. Assim, o setor florestal, mediante a industrialização madeireira, tornou-se uma das principais atividades econômicas recorrentes dos Estados contidos na região amazônica [17].

Em função de sua grande complexidade, a madeira é uma matéria prima que deve ser utilizada de forma adequada, maximizando o seu uso. No entanto, a partir das altas taxas de desmatamento na Amazônia e do baixo aproveitamento da madeira, mostrou-se uma vulnerabilidade da sustentabilidade das atividades ligadas à exploração desta matéria prima. Assim, a melhoria do nível tecnológico industrial é uma condição essencial para o aproveitamento máximo da matéria-prima e está diretamente relacionado com a conservação dos recursos florestais [3].

Atualmente, estudos mostram o baixo rendimento volumétrico de madeira serrada na região amazônica $[8,3,9]$ resultando altas taxas de geração de resíduos [6]. Além disso, a própria legislação vigente determina a comercialização de apenas $35 \%$ do volume estimado de madeira [5], sendo os outros $65 \%$ caracterizados como resíduos florestais. Existe ainda, alguns casos que, conforme a metodologia utilizada durante o processo de desdobro das toras, o rendimento volumétrico possa ser menor que o estabelecido pela legislação [3]. Por isso, é imprescindível a busca por soluções que mitiguem esse passivo, para que a utilização da madeira de espécies amazônicas possa ser realmente en carada como uma atividade sustentável.

Com isso, o baixo rendimento volumétrico pode ser justificado pela falta de tecnologia empregada nas indústrias madeireiras da região, atrelado ao mesmo, o grande índice de geração dos mais diversos tipos de resíduos madeireiros. Assim, além do desenvolvimento tecnológico no processo de desdobro da madeira, também devem existir alternativas sustentá veis visando a sua máxima utilização.

A geração de resíduos na indústria florestal no Brasil tem mostrado valores expressivos, ocasionando o baixo rendimento de madeira nas serrarias [3,13], onde o índice de aproveitamento da matéria prima pode variar entre $25 \%$ a $70 \%$ do volume da tora [3], o que leva a considerar seriamente a sua utilização na cadeia produtiva, pois não representa só um problema econômico, por meio do desperdício, como também um sério problema de caráter ambiental [1].

Assim, o termo sustentabilidade ligado às áreas de Manejo Florestal Sustentável (área de exploração florestal efetiva e certificada), deve oferecer produtos inovadores, proporcionando o melhor aproveitamento do indivíduo arbóreo como um todo, valorizando-o como recurso florestal, sendo esse realizado por meio do aumento do rendimento volumétrico de madeira serrada, como também, de um maior uso dos resíduos florestais, reinserindo-os na cadeia produtiva para a confecção de produtos com alto valor comercial.

A madeira é um material suscetível ao ataque de organismos degradadores, conhecidos como xilófagos, que podem causar diversos danos ao estado da qualidade de madeira serrada. A tora oca é uma das formas de diminuição da qualidade da madeira, por essas apresentarem alto nível de degradação, diminuição do volume por indivíduo e dificuldade no processamento mecânico. Existem poucas literaturas que justifiquem de uma forma clara, a exploração ou não de árvores que possuam tal deformidade para a produção de madeira serrada, sendo o seu corte bastante questionável, tanto do ponto de vista ecológico como econômico. Para TROCKENBRODT [20], árvores ocas são passíveis de exploração, produzindo madeira de boa qualidade e que podem gerar um incremento econômico considerável às serrarias, já que, para o autor, não faz sentido diminuir o número de árvores exploráveis pela presença de ocosidade no tronco, se o rendimento volumétrico dessas tendem a ser positivo com a aplicações de técnicas de corte.

No entanto, o processamento mecânico de toras ocas é bastante questionável, já que podem gerar um baixo rendimento volumétrico de madeira serrada, como também, alta geração de resíduos madeireiros. O desdobro das toras, sem a presença de ocosidade, normalmente acontece pelo sistema de corte tangencial, onde a tora é fatiada para a obtenção do maior número de peças, em um menor intervalo de tempo [14]. Tal método ao ser aplicado ao desdobro das toras ocas se torna inviável pela presença da cavidade, muitas vezes centralizada ao diâmetro da tora, podendo o oco estar tanto nas extremidades, como percorrer por todo o comprimento do fuste.

Em municípios do estado do Amazonas, marceneiros e carpinteiros atuam na fabricação de móveis e artefatos diversos de madeira oriundos de resíduos de processamento mecânico ou desdobro da madeira. Nesses processos de fabri- 
cação, o que pode ser observado é a afirmativa, repassada culturalmente de pai para filho, que um móvel de madeira é mais resistente e duradouro se a sua estrutura conter uma quantia maior de matéria-prima com dimensões avolumadas. Nesses casos, pode-se observar a falta de aplicação e utilização de conceitos envolvendo tecnologia da madeira e Design.

Essa não utilização do Design, na maioria dos casos, acontece por conta do conceito de que o mesmo está relacionado apenas ao desenvolvimento de itens de luxo e beleza, ligado à 'bela forma' e à arte [10]. Quanto a isso, BONSIEPE [4] afirma que "no senso comum, o termo Design está fortemente associado as atividades estético-formais".

Conforme MANZINI e VEZZOLI [12], a fim de minimizar recursos no desenvolvimento de produtos sustentáveis, se faz necessário seguir algumas diretrizes como:

- Minimizar o conteúdo material de um produto;

- Minimizar as perdas e os refugos;

- Minimizar o consumo de energia para a produção;

- Minimizar o consumo de recursos no desenvolvimento dos produtos.

Estudos realizados indicam que umas das alternativas para maximização do aproveitamento da madeira, proveniente de resíduos florestais e de processamento mecânico, pode ocorrer por meio da aplicação de técnicas de Design, formando produtos diferenciados e de qualidade satisfatória. Dentre esses, o estudo de CASTRO et al. [7], NASCIMENTO et al. [15], SILVA et al. [19], buscaram exaltar características intrínsecas das madeiras, mesclando variedades em um mesmo produto, como diferentes tipos de resíduos (aparas, costaneiras e disco) e a utilização de mais de uma única espécie arbórea, além do uso de peças com imperfeições ocasionadas por ataque de fungos e coleópteros (besouros).

A partir desses trabalhos, pode-se observar que as soluções apresentadas por meio do Design possibilitam um novo olhar sobre a utilização de resíduos madeireiros, resultando em alternativas de produtos sustentáveis. Dessa forma, o objetivo da pesquisa foi desenvolver produtos a partir de uma visão holística do processo, projetando, confeccionando e verificando as etapas de processamento, para atestar o aumento do rendimento volumétrico e a diminuição dos resíduos de madeiras provenientes de árvores ocas.

\section{MATERIAIS E MÉTODOS}

A matéria prima desta pesquisa foi coletada na empresa Mil Madeiras Preciosas Ltda., situada no município de Itacoatiara, no Estado brasileiro do Amazonas, sendo a sua sede localizada na coordenada $3^{\circ} 04^{\prime}$ ao Sul e $58^{\circ} 57^{\prime}$ a Oeste. Para obtenção da matéria prima, foi realizado um diagnóstico prévio da existência de toras ocas no pátio da empresa. Em seguida, foram selecionadas duas toras ao acaso, conforme a disponibilidade no pátio e concessão da empresa, sendo as mesmas transportadas até o laboratório de Engenharia de Artefatos de Madeira - LEAM da Coordenação de Tecnologia e Inovação - COTEI do Instituto Nacional de Pesquisas da Amazônia - INPA, para cubagem das toras, desdobro das toras em peças com tamanhos variados pela inconformidade da ocosidade e usinagem das peças obtidas. A madeira utilizada é conhecida popularmente como Muiracatiara (Astronium lecointei Ducke) e possui densidade alta, com grã regular, textura média, não possui cheiro e gosto característicos.

A obtenção do volume real das toras ocas consistiu na realização da cubagem da tora com casca e do oco da tora pelo método de Smalian, de acordo com a equação 1, mensurando os diâmetros das extremidades da tora e do oco $\left(D_{l} \mathrm{e}\right.$ $D_{2}$ ), para que assim, fosse obtida a diferença dos dois volumes, determinando a volumetria real de cada tora oca $(V t)$.

$$
\mathrm{Vt}=\frac{\left(\frac{\pi * D_{1}{ }^{2}}{40000}\right)+\left(\frac{\pi * D_{2}{ }^{2}}{40000}\right) * L}{2}
$$

Em seguida, foi realizado o desdobro das duas toras ocas para a obtenção de peças com medidas pré-definidas, de acordo com a nomenclatura proposta pelo Conselho Nacional do Meio Ambiente (CONAMA) n 474/2016 [5]. No entanto, ainda há certa dificuldade no desdobramento das toras ocas na região amazônica, já que muitos processadores não realizam o corte direcionado, mas sim, o corte tangencial. Além de ganhos na qualidade e em estética na formação do produto final, o corte direcionado também proporciona a maximização da madeira por tora, ou seja, o aumento do rendimento volumétrico. No entanto, o corte tangencial é o mais praticado pela obtenção de ganhos econômicos para a empresa processadora de madeira, como a diminuição do tempo de desdobro por tora e facilidade de tal operação.

Neste estudo, em razão dessas particularidades apontadas acerca da presença de espaços vazios no interior das toras, as mesmas foram desdobradas de acordo com o formato da ocosidade, efetuando cortes no sentindo tangencial (método convencional), e posteriormente cortes no sentido radial (corte que proporciona ganhos em qualidade), de acordo com o sistema de desdobro misto (Figura 1). 


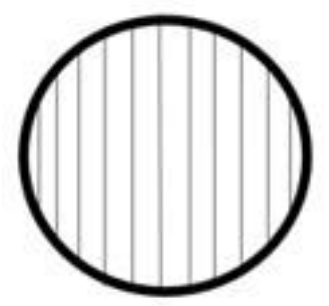

A

A) Desdobro Tangencial

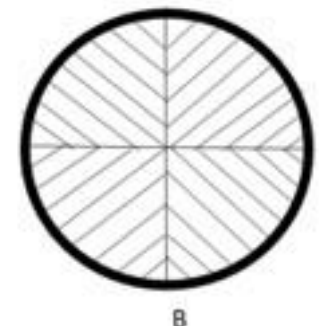

B) Desdobro Radial



C) Desdobro Misto

Figura 1: Vista do topo da tora, demonstrando os tipos de desdobro da madeira.

Para a determinação do rendimento de madeira, o Coeficiente de Rendimento Volumétrico - (CRV) foi considerado, de acordo com Equação 2, permitindo a obtenção da quantidade em $\mathrm{m}^{3}$ de madeira aproveitada após a conversão de tora e torete para madeira serrada e produto acabado $(V m s)$. As peças desdobradas foram organizadas em pilhas, espaçadas por separadores com dimensões similares, permitindo a circulação do ar e evitando o empenamento das peças. Após a seleção aleatória de algumas peças obtidas do desdobramento, foi realizada a usinagem da madeira, sendo as medidas de largura, espessura e comprimento necessárias para a determinação do volume e rendimento final da madeira.

$$
R(\%)=\frac{V_{m s}}{V_{t}} * 100
$$

Atrelado às diretrizes de design para a sustentabilidade, a confecção de um móvel baseado nessa madeira proveniente das toras ocas foi idealizada, atendendo a demanda do desenvolvimento de produtos a partir de tecnologias aplicadas ao processamento mecânico da madeira. Para um melhor aproveitamento da matéria prima, foi desenvolvida a alternativa de confecção de uma mesa de jantar de seis lugares, a partir da metodologia proposta por BARBOSA FILHO [2], a qual considerou: o levantamento da demanda, construção do conceito, definição do funcional, geração de alternativas, materialização de alternativas, realização de testes e refinamentos e apresentação da solução final. Essa estratégia visou atender as diretrizes de design para a sustentabilidade, minimizando do uso de recursos na produção.

Atualmente, a estrutura mais comum no mercado para as mesas de jantar é representada, em sua descrição mais simplificada, pela disposição de quatro pernas, tampo retangular e elementos de ligação. Com o aumento da concorrência, várias empresas são incentivadas a apresentarem produtos com formas e materiais diversos, atentando, na maioria das vezes, a questões ergonômicas e antropométricas. Durante a etapa de construção de conceito, foi realizado um levantamento de produtos similares para a mesa de jantar de seis lugares, visando identificar as tendências de mercado, materiais mais utilizados e formatos disponíveis.

Os tampos das mesas, em sua maioria, possuíam o formato retangular, mas encontraram-se mesas triangulares, com tampo integralmente produzido em vidro. A partir disso, um estudo de formas geométricas foi feito para a definição funcional da alternativa de mesa de jantar, levando em consideração o requisito do menor consumo de matéria-prima.

A forma geométrica base utilizada durante a geração de alternativas foi aquela do triangulo isósceles (Figura 2). $\mathrm{O}$ formato do mesmo permitiu uma dimensão maior ao tampo da mesa, atendendo o dimensionamento básico para comportar seis pessoas confortavelmente, bem como utilizando menor quantidade de material. 


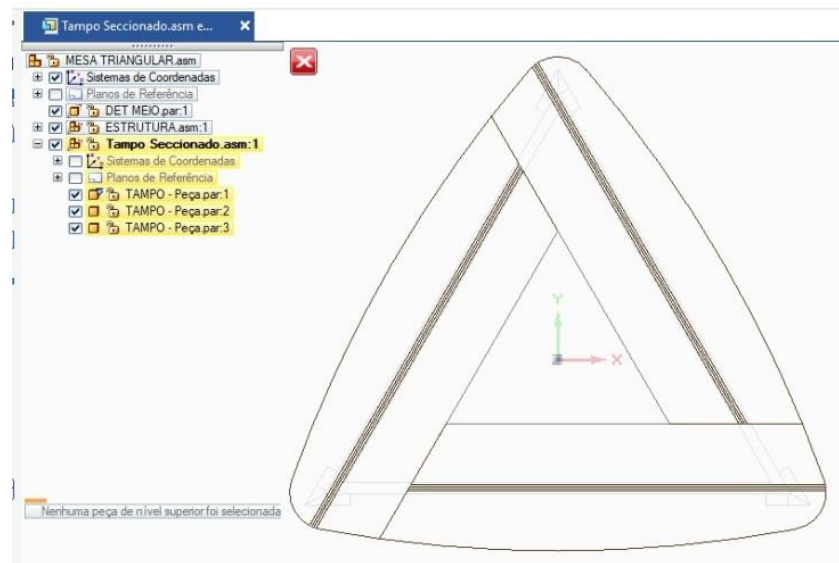

Figura 2: Forma atribuída ao tampo da mesa, vista de topo.

O estudo de formas foi realizado a partir de desenhos em papel e por meio do software CAD Solid Edge St10 (Figura 3). A alternativa foi modelada no mesmo software para obtenção da visualização 3D, detalhamento técnico, simulação de encaixes, montagem e desmontagem entre as peças (Figura 4). Esse processo permitiu a prototipagem digital eliminando a necessidade de confecção de protótipo físico iniciais, evitando o desperdício de materiais.

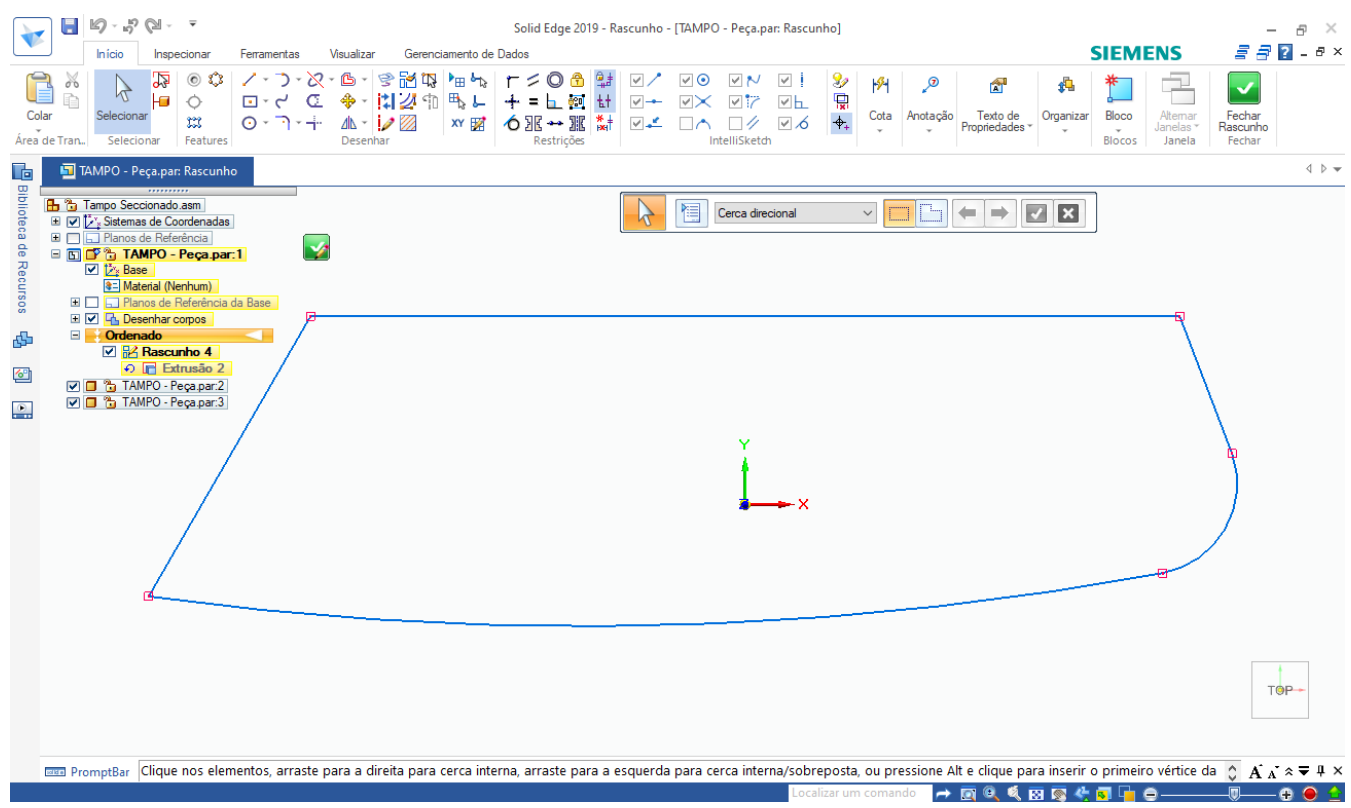

Figura 3: Interface do Softawre CAD Solid Edge St10. 


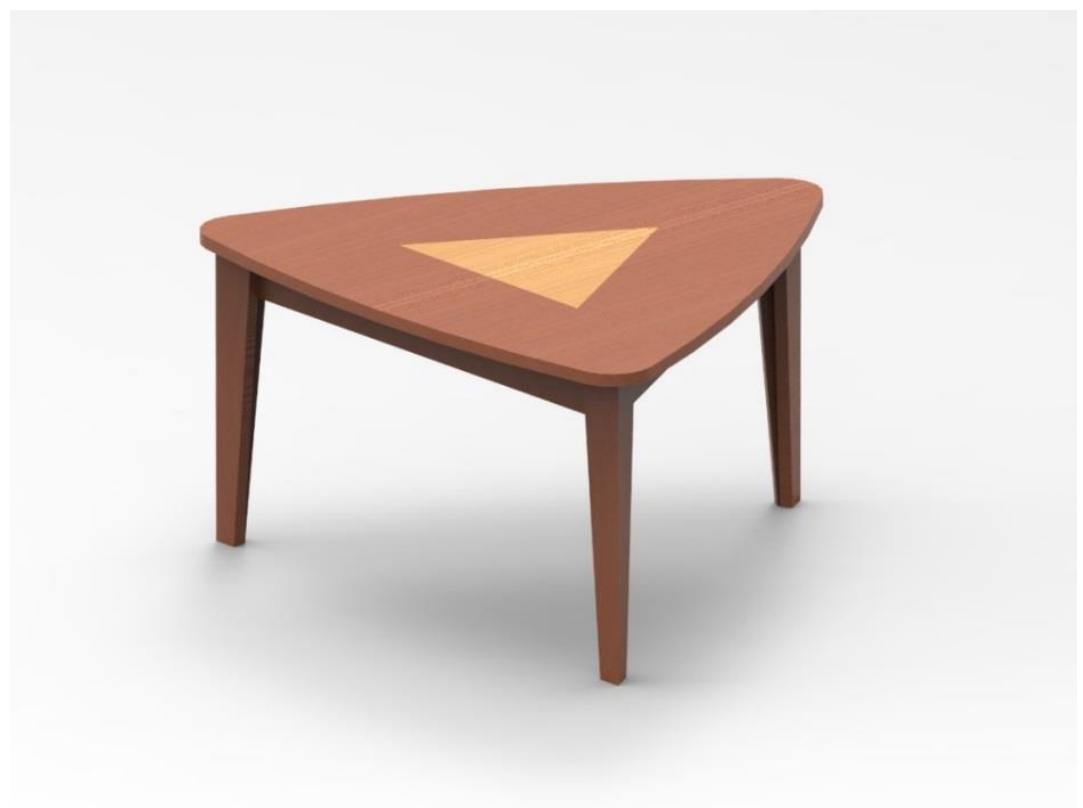

Figura 4: modelagem e renderização para visualização 3D da mesa de jantar.

Somente após todos os ajustes terem sido realizados no protótipo digital é que se iniciou a etapa de materialização da alternativa selecionada. A execução desse produto foi realizada a partir dos maquinários dispostos na serraria: serra fita e circular, plaina desempenadeira e desengrossadeira, furadeira horizontal e vertical, tupia manual e lixadeiras (disco, rolo e elétrica manual).

Por fim, a condição da inserção da madeira proveniente de tora oca para a confecção de uma mesa de jantar foi verificada, proporcionando o aumento do aproveitamento de madeira nas indústrias pela diminuição do dimensionamento das peças utilizadas nos móveis, assim como, a utilização de seus resíduos.

\section{RESULTADOS}

A duas toras referentes à madeira da espécie Astronium lecointei Ducke corresponderam a um volume total de 2,42 $\mathrm{m}^{3}$ de madeira, onde foram processadas utilizando um motosserra de pequeno porte por meio do sistema de desdobro misto. As peças selecionadas, correspondente a cerca de $7 \%$ do total de madeira das duas toras, ou seja, igual a $0,179 \mathrm{~m}^{3}$ de madeira, foram beneficiadas e realizada a usinagem para a confecção da mesa de jantar. Ao finalizar o processamento do produto, todas as peças (como as pernas, o aro e o tampo da mesa) foram mensuradas, sendo suas medidas em espessura (e), largura (l) e comprimento (c) detalhadas na Tabela 1 , resultando na volumetria total de $0,0502 \mathrm{~m}^{3}$ de madeira utilizada nas peças do protótipo da mesa de jantar.

O tampo da mesa foi construído a partir de três partes que, com a junção dessas, formam um triângulo isósceles, como já mencionado. No entanto, para cada parte do tampo, foram utilizadas as peças denominadas: tampo externo, tampo interno, lâmina e lâmina Marupá, sendo esta última, utilizada a madeira da espécie Marupá (Simarouba Amara Aulb.) para aplicação de uma técnica bastante usada por artesãos regionais, para agregar valoração estética ao produto. 
Tabela 1: Medidas das peças da mesa de jantar

\begin{tabular}{c|c|c|c|c}
\hline PEÇAS & QUANTIDADE & $\boldsymbol{e}(\mathbf{c m})$ & I (cm) & $\mathbf{c ~ ( c m ) ~}$ \\
\hline Tampo externo & 3 & 2,6 & 16 & 118 \\
\hline Tampo interno & 3 & 2,6 & 16 & 104 \\
\hline Lâmina & 3 & 2,6 & 0,5 & 112 \\
\hline Lâmina Marupá & 6 & 2,6 & 0,5 & 112 \\
\hline Aro da mesa & 3 & 3 & 12 & 125 \\
\hline Perna da mesa & 6 & 3 & 3 & 72 \\
\hline
\end{tabular}

$\mathrm{e}=$ espessura, $\mathrm{l}=$ largura, $\mathrm{c}=$ comprimento

Com isso, o Coeficiente de Rendimento Volumétrico do produto, ao qual tem por finalidade estimar o aproveitamento de madeira utilizada para a confecção da mesa de jantar, foi igual a 30,13\%; valor considerado alto, já que a quantidade de madeira serrada utilizada para a produção do protótipo foi superior ao exigido pelo CONAMA 474/2016 (35\% de madeira serrada) anteriormente citado.

A vista do desenho técnico, dimensionamento das peças e outras informações sobre a mesa de jantar é demonstrada de acordo com a Figura 5. Nessa ilustração, é possível verificar as formas geométricas das peças e o encaixe de cada uma, para formar os principais suportes da mesa, como as pernas, o aro e o tampo. A mesa foi confeccionada com uma estrutura distinta das convencionais, por possuir um tampo de formato triangular com bordas arredondadas e em seu centro, também com formato triangular, inserido uma peça de vidro temperado. As pernas apresentaram-se com um dimensionamento diferenciado a medida do alcance do chão, ou seja, extremidade inferior distinta da superior. 

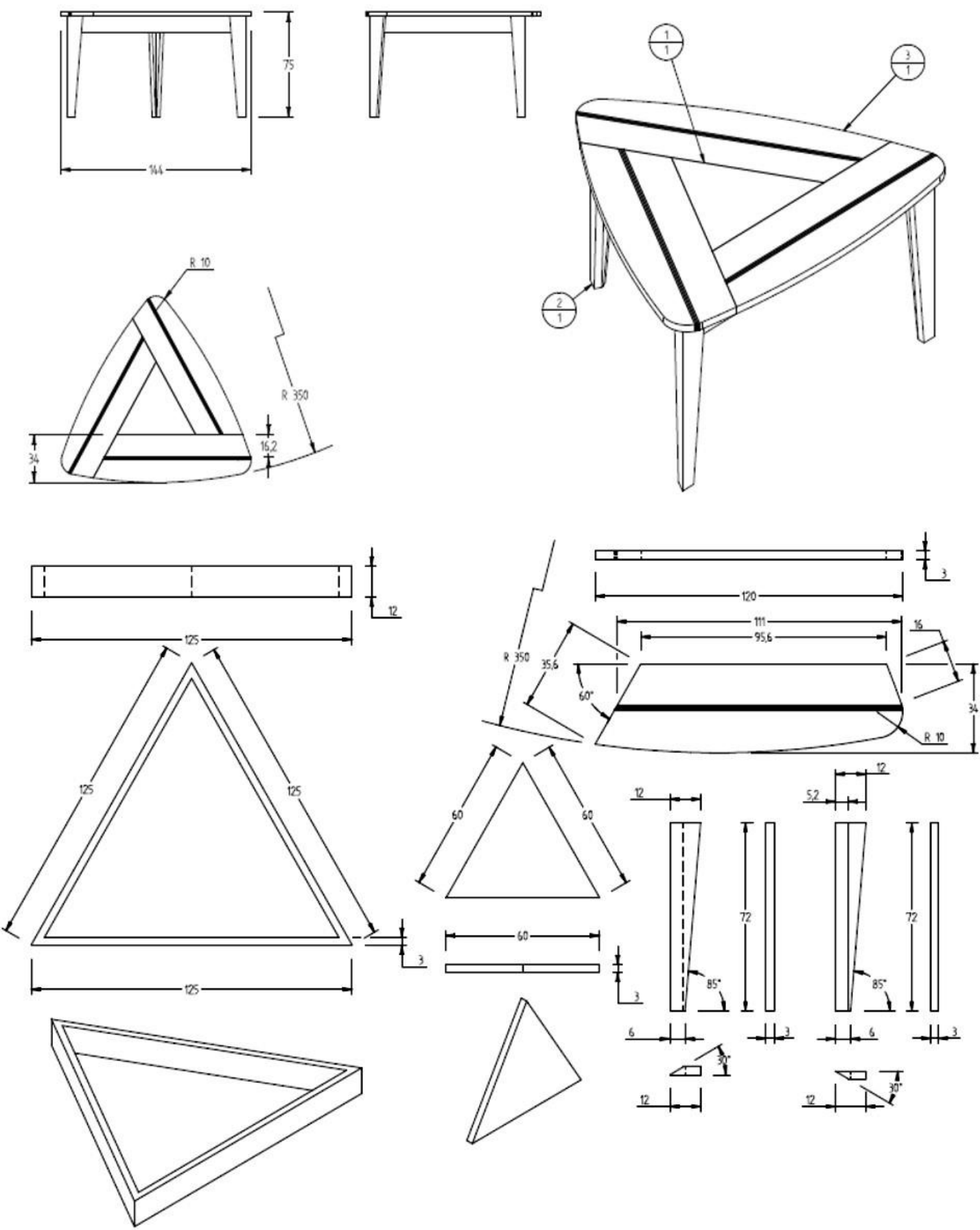

Figura 5: Formas e dimensionamento das peças de madeira utilizadas na mesa de jantar.

O resultado do produto confeccionado nesta pesquisa é mostrado na Figura 6, sendo possível a visualização dos detalhes da perna e do tampo da mesa de jantar que foram feitos a partir da técnica de marchetaria, ao qual consiste na incrustação de diferentes tipos de madeira. Nesse processo foi utilizada lâminas de Marupá (Simarouba Amara Aulb.) com espessura de $3 \mathrm{~cm}$ x $0,5 \mathrm{~cm}$ x $112 \mathrm{~cm}$, que realizou um contraste ao tampo, já que essa madeira é mais clara que a madeira de Muiracatiara. Com isso, a técnica de marchetaria contribuiu para um design diferenciado do tampo da mesa, sendo agradável ao consumidor à nível visual e estético. Com isto, a técnica de marchetaria contribuiu para um melhor aproveitamento de material, uma vez que permitiu a junção de peças mais estreitas de madeira resultando em uma única peça maior, que ao ser montada com as demais resultou em um tampo de mesa diferenciado, além de atender critérios à nível visual e estético. 

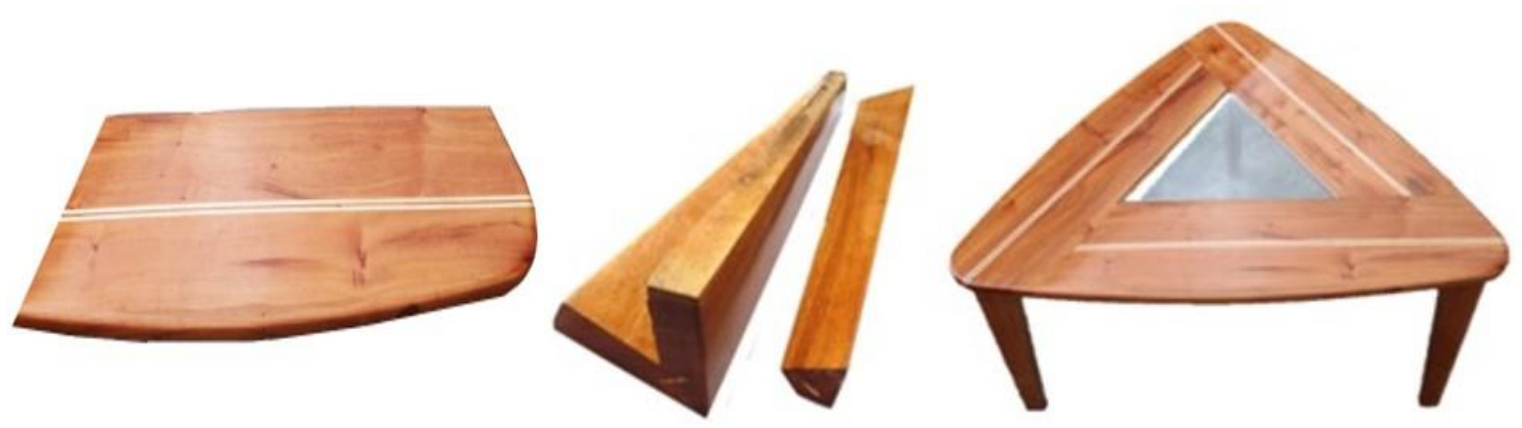

Figura 6: Mesa de jantar para seis lugares, utilizando madeira proveniente de árvore oca, da espécie de Muiracatiara e lâminas de Marupá, configurando a técnica de marchetaria.

Pelo fato da madeira ser proveniente do aproveitamento de árvore com ocosidade, as peças possuíram algumas características imperfeitas (com presença de ataque de organismos xilófagos), as quais não se tornaram um problema na concretização do produto, já que não foi constatada a diminuição de resistência mecânica das peças da mesa de jantar. Além disso, o emprego da marchetaria permitiu o uso de peças menores, se comparado às mesas com tampos integralmente maciços, isto é, formados por uma única peça.

Para o acabamento de superfície das peças do produto, foi utilizado verniz poliuretano bi-componente, apresentando excelentes resultados. Também foram utilizados detalhes em inox, como o parafuso, usado para fixar as pernas com o aro da mesa, assim como, o detalhe de uma peça de 5 centímetros de altura na extremidade das pernas, em contato com o chão, configurando a altura padrão para uma mesa de jantar, mostrados na Figura 7.
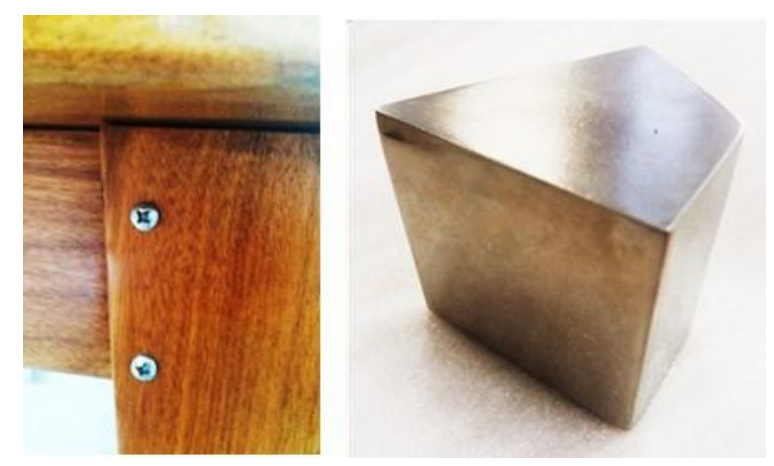

Figura 7: Detalhes em inox utilizados nas pernas da mesa de jantar para seis lugares.

\subsection{Aproveitamento do resíduo após o processamento do móvel}

Como relatado no início deste trabalho, há a geração de diversos tipos de resíduos na indústria madeireira. Mesmo com todo o processo de desenvolvimento visando o menor desperdício de materiais durante a materialização da mesa foram gerados resíduos madeireiros de processamento mecânico com peças de excelente qualidade.

A partir do coeficiente de rendimento volumétrico, foi possível estimar a quantidade de resíduos gerados durante o processamento da madeira para a elaboração da mesa, sendo esse valor igual a $69,87 \%$ do total de madeira utilizada, onde os principais tipos de resíduos foram: serragem, aparas, cavacos e ripas. No entanto, destaca-se que esses resíduos foram essencialmente oriundos das toras ocas, as quais possuem menor aproveitamento e aplicação industrial na região.

Pela forma e qualidade em que os resíduos gerados se apresentavam após a finalização da mesa de jantar, optou-se pela confecção de um novo produto. Após a análise das peças que possuíam dimensões pequenas, foi idealizada uma luminária de mesa, a fim de utilizar os resíduos, tal qual como gerados. Assim, as peças dos resíduos provenientes do processamento mecânico da mesa foram utilizadas sem sofrer qualquer outro tipo de processamento, onde foi realizado somente o encaixe das peças, com pequenos ajustes e atribuindo elementos como fiação, lâmpada e elementos de ligação. Ressalta-se que a construção de um outro produto utilizando os resíduos do produto principal (mesa de jantar) não foi inicialmente planejado, logo, a alternativa da luminária não seguiu a metodologia utilizada para confecção da mesa de jantar. O resultado des- 
se produto, com resíduos gerados principalmente do tampo da mesa de jantar, pode ser visto na Figura 8.
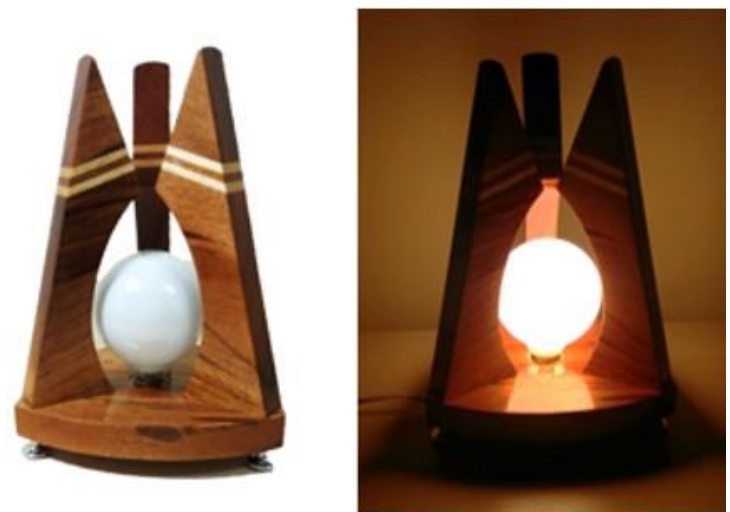

Figura 8: Luminária de mesa confeccionada a partir de resíduos da usinagem da mesa de jantar.

\section{DISCUSSÃO}

Assim como na pesquisa de PEREIRA [18], a prototipagem para os produtos confeccionados neste estudo, se caracterizou como sendo a materialização da melhoria dos móveis e artigos de madeira em geral, sendo destacada a implementação de novos processos tecnológicos para utilização de madeiras de árvores ocas, obtendo produtos inovadores e com alta valoração no setor madeireiro.

Dessa forma, os produtos confeccionados, mesa de jantar e luminária, apresentaram bons resultados, sendo os mesmos destacados quanto a:

- Minimização de conteúdo material de um produto;

Uma vez que as formas empregadas durante o desenvolvimento da alternativa da mesa possibilitaram o uso de pouca quantidade de madeira, validando dessa forma a utilização de matéria prima oriunda de árvores ocas, demonstrando ótimo rendimento na confeç̧ão de produtos projetados para serem sustentáveis, justificado pelo uso da volumetria líquida de $0,0502 \mathrm{~m}^{3}$ de madeira em relação ao volume bruto de $2,42 \mathrm{~m}^{3}$ de madeira em tora.

- Minimização de perdas e refugos;

Os resíduos madeireiros de processamento mecânico gerados durante o processo de fabricação da mesa de jantar foram aproveitados para a confeç̧ão de luminária, sendo possível minimizar perdas no processamento mecânica da madeira, a partir de uma nova ótica sobre tais resíduos.

- Minimização do consumo de energia para a produção;

As formas empregadas aos produtos e planejamento para o processo de fabricação resultaram num menor consumo de recursos humanos e energéticos para a produção dos objetos.

- Minimização do consumo de recursos no desenvolvimento dos produtos.

A partir da modelagem 3D foi possível prototipar virtualmente as alternativas, verificar dimensões, realizar correções e gerar o detalhamento técnico para então confeccionar os produtos. Essa etapa permitiu a minimização de recursos para o desenvolvimento dos produtos, envolvendo desde a não utilização de folhas de papel, uma vez que correções e anotações relacionadas aos produtos foram realizadas no campo virtual, até o não desperdício de materiais a fim de confeccionar protótipos que permitissem a visualização, uma vez que o software CAD possibilitava esse recurso e mais outros.

Pelos pontos positivos identificados durante o processo de fabricação e conclusão da mesa, pode ser enfatizado que a mesma poderá ser reproduzida em larga escala, por pequenos e médios produtores de móveis, como também aumentar fonte de renda dos artesãos por estar subsidiando os resíduos pós-fabricação para a produção das luminárias, considerando que toda mesa fabricada possibilita a obtenção de uma luminária, proporcionando um ambiente sustentável de economia circular para essas atividades produtivas regionais.

\section{CONCLUSÕES}

Os produtos gerados a partir de modelagem virtuais com softwares especializados, permitiu maior controle do beneficiamento e usinagem da madeira, aumentando o rendimento volumétrico da madeira e reduzindo a geração de resíduos florestais.

Com o conhecimento da tecnologia da madeira e do design de produto é possível agregar valor as ma- 
deiras de espécies arbóreas da Amazônia, assim como aproveitamento de tora oca.

Foi possível confeccionar produtos de grande aceitação no mercado e de fino acabamento a partir de madeira proveniente de toras ocas, permitindo a maximização dos recursos florestais, independente do estado e qualidade ao qual se encontra, contribuindo para o Manejo Florestal Sustentável na Amazônia.

\section{BIBLIOGRAFIA}

[1] ARAÚJO, H.J.B., Aproveitamento de resíduos das indústrias de serrarias do Acre para fins energéticos, 1 ed. Rio Branco, Acre: EMBRAPA, 2003.

[2] BARBOSA FILHO, A.N. F. Projeto e desenvolvimento de produtos. Atlas, São Paulo, 2009.

[3] BIASI, C.P., ROCHA, M.P., "Rendimento em madeira serrada e quantificação de resíduos para três espécies tropicais", Revista Floresta, v. 1, n. 37, pp. 95-108, Abr. 2007.

[4] BONSIEPE, G., Design, Cultura e Sociedade, 1 ed., São Paulo: Blucher, 2011.

[5] BRASIL. Resolução do Conselho Nacional do Meio Ambiente - CONAMA, nº 411, de 6 de abril de 2016. Dispõe sobre os procedimentos para inspeção de indústrias consumidoras ou transformadoras de produtos e subprodutos florestais madeireiros de origem nativa. Diário Oficial da União: seção 1, Brasília, DF, n 82, p. 74, 2 mai. 2016.

[6] BRAZ, R.L., NUTTO, L., BRUNSMEIER, M., et al., "Resíduos da colheita florestal e do processamento da madeira na Amazônia - uma análise da cadeia produtiva", Journal of Biotechnology and Biodiversity, v. 5, n. 2, pp. 168-181, Mai. 2014.

[7] CASTRO, P.RS., NASCIMENTO, C.C., ARAÚJO, R.D., "Móveis funcionais e decorativos com resíduos de madeiras Amazônicas" In: XIII Jornada de Iniciação científica do PIBIC/CNPq/FAPEAM/INPA, pp. 316317, Manaus, Amazonas, 2004.

[8] CLEMENT, C.R., HIGUCHI, N., "A floresta amazônica e o futuro do Brasil", Ciência e Cultura (SBPC), v. 58 , pp. 44-49, 2006.

[9] DANIELLI, F.E., GIMENEZ, B.O., OLIVEIRA, C.K.A., et al., "Modelagem do rendimento no desdobro de toras de Manilkara spp. (Sapotaceae) em serraria do estado de Roraima, Brasil”. Scientia Forestalis, v. 44, n. 111, pp. 641-651, Set. 2016.

[10] FORNASIER, C.B.R., MARTINS, R.F.F., MERINO, E., Da responsabilidade social imposta ao design social movido pela razão. Repositório Institucional UFSC. 2004.

https://repositorio.ufsc.br/handle/123456789/1850. Acessado em novembro de 2019.

[11] HIGUCHI, N., SANTOS, J., TEIXEIRA, L.M., et al., "O mercado internacional de madeira tropical está à beira do colapso". SBPN Scientific Journal, v.1-2, pp. 33-41, 2006.

[12] MANZINI, E., VEZZOLI, C., O Desenvolvimento de Produtos Sustentáveis: os requisites ambientais dos produtos industriais, 1. ed. São Paulo, Editora da Universidade de São Paulo, 2016.

[13] MARCHESAN, R., LOIOLA, P.L., JUIZO, C.G.F., et al., "Rendimento em madeira serrada de três espécies amazônicas para duas classes de qualidade", Ciência da Madeira, v. 9, n. 3, pp.143-151, Set. 2018.

[14] MURARA JUNIOR, M.I., ROCHA, M.P., TIMOFEICZYK JUNIOR, R., "Rendimento em madeira serrada de Pinus taeda para duas metodologias de desdobro", Revista Floresta, v. 35, n. 3, pp. 473-483, Dez. 2005.

[15] NASCIMENTO, C. C. ; ROCHA, J.A. ; HIGUCHI, M.I.G., et al., O uso de madeiras de árvores caídas em comunidades extrativistas: Estratégia econômica e de sustentabilidade ambiental, pp. 48, Manaus, Amazonas, 2010.

[16] OLIVEIRA, A.N., AMARAL, I.L., "Florística e fitossociologia de uma floresta de vertente na Amazônia Central, Amazonas, Brasil”, Acta Amazônica, v. 34, n. 1, pp. 21-34, Abr. 2004.

[17] PEREIRA, D., SANTOS, D., VEDOVETO, M., et al., Fatos Florestais da Amazônia. Belém, Pará: Imazon, 2010.

[18] PEREIRA, A.F., "Design para a sustentabilidade: melhoria de produtos e processos e valorização da identidade local", Estudos em Design, v. 20, n. 2, pp. 1-15, Out. 2012.

[19] SILVA, G.M., NASCIMENTO, C.C., SILVA, J.M.M., "Concepção de produtos para a utilização de resíduos madeireiros de espécies arbóreas da Amazônia”, Blucher Design Proceedings, v. 6, n. 1, pp.1-14, Mar. 2019. 
[20] TROCKENBRODTA, M., IMIYABIRB, Z., JOSUE, J. "Hollow logs and logging residues from Deramakot Forest Reserve, Sabah, Malaysia", Forest Ecology and Management, v. 165, n. 1-3, pp. 141-150, Jul. 2002.

\section{ORCID}

Suzana Helen da Silva Medeiros Claudete Catanhede do Nascimento Geislayne Mendonça Silva https://orcid.org/0000-0001-8581-2232

https://orcid.org/0000-0001-7048-3720

https://orcid.org/0000-0002-7173-2415 